\title{
Un fantasma recorre el Uruguay: la reemergencia charrúa en un "país sin indios"
}

\begin{abstract}
A Spectre Is Haunting Uruguay: The Charrua Reemergence in "a Country without Indians" Um fantasma percorre o Uruguai: a reemergência charrúa num "país sem índios"
\end{abstract}

\section{Gustavo Verdesio}

UNIVERSITY OF MICHIGAN, ANN ARBOR, ESTADOS UNIDOS

Profesor del Departamento de Lenguas y Literaturas Romances en la

University of Michigan, Ann Arbor. PhD Northwestern University.

Es autor de Forgotten Conquests. Re-reading New World History

from the Margins (Temple University Press, 2001) y editor, junto

con Álvaro F. Bolaños, de Colonialism Past and Present. Reading and Writing about Colonial Latin American Texts Today (SUNY

University Press, 2002). Correo electrónico: verdesio@umich.edu

\section{Artículo de reflexión}

El presente artículo es parte del proyecto de investigación dedicado a la reemergencia de etnicidades indígenas en Uruguay y Argentina. Partes del mismo fueron publicadas en la revista Lento, de Uruguay, en octubre del 2013.

Documento accesible en línea desde la siguiente dirección: http://revistas.javeriana.edu.co

doi:10.11144/Javeriana.CL18-36.frur 


\section{Resumen}

Este trabajo estudia la reemergencia de la etnicidad charrúa en Uruguay, un país que se ha imaginado a sí mismo, por lo menos desde fines del siglo XIX, como carente de indígenas. En el marco de un clima relativamente reciente de descolonización y de avance de las agendas políticas y sociales indígenas, los militantes de los grupos reemergentes presentan un desafío importante a las narrativas de la nación predominantes en Uruguay.

Palabras clave: charrúas; colonialismo de colonos; definiciones de Cultura; estrategias de invisibilización de indígenas; reemergencias étnicas indígenas; Uruguay; América Latina

\section{Abstract}

This paper discusses the reemergence of Charrua ethnicity in Uruguay, a country that has imagined itself, since de second half of the eighteenth century, as one without indigenous inhabitants. In a relatively recent framework of decolonization that has made possible the advancement of indigenous political and social agendas, the activists of the reemergent groups constitute a serious challenge to the predominant Uruguayan national narratives.

Keywords: Charrua people; colonialism; definitions of culture; indigenous ethnic emergences; strategies for the visibility of indigenous inhabitants; Uruguay; Latin America

\section{Resumo}

Este trabalho estuda a reemergência da etnicidade charrúa no Uruguai, um país que tem se imaginado a si próprio, pelo menos desde finais do século XIX, como carente de indígenas. Enquadrado em um clima relativamente recente de descolonização e avanço das agendas políticas e sociais indígenas, os militantes dos grupos reemergentes apresentam desafio importante às narrativas da nação predominantes em Uruguai.

Palavras-chave: charrúas; colonialismo de colonos; definições de Cultura; estratégias de invisibilização de indígenas; reemergencias étnicas indígenas; Uruguai; América Latina

RECIBIDO: 16 DE ENERO DE 2014. APROBADO: 5 DE FEBRERO DE 2014. DISPONIBLE EN LÍNEA: 30 DE JULIO DE 2014.

\section{Cómo citar este artículo:}

Verdesio, Gustavo. "Un fantasma recorre el Uruguay: la reemergencia charrúa en un "país sin indios"”. Cuadernos de Literatura 18.36 (2014): 86-107. http://dx.doi.org/10.11144/Javeriana.CL18-36.frur 
URUGUAY ES UN país que se piensa a sí mismo como "país sin indios". La imagen que predomina (y que el Estado ha contribuido a construir) es la de una sociedad conformada por gran número de ciudadanos de ascendencia europea, con valores occidentales y vocación cosmopolita. Durante décadas, las narrativas de la nación han ido relegando a los indígenas a un papel meramente decorativo y distante, a un elemento casi exótico en la historia del país. El éxito del discurso que declara la extinción de los indígenas, promovido por los aparatos de reproducción ideológica del Estado a través de textos de educación primaria y secundaria y de maestros y profesores influidos por libros de divulgación que pasan por científicos, es casi total. Una extinción que es imaginable gracias a que en algunas sociedades (como Estados Unidos, Argentina y Uruguay) ha existido lo que Claudia Briones llama una convicción articulante de los discursos y narrativas de la nación, que consiste en postular la posibilidad de anulación virtual de toda diferencia (La alteridad 80). En ese marco ideológico, el mito que postula que Tacuabé, Vaimaca Pirú, Guyunusa y Senaqué (los falazmente llamados "últimos charrúas", llevados a Francia para ser exhibidos, y luego estudiados, como rareza o como representantes de la barbarie) fueron los últimos representantes de la etnia charrúa, ha contribuido a darle un cierre casi poético a la narrativa de la extinción, pero el broche de oro para ella lo constituye el poema Tabaré, de Juan Zorrilla de San Martín, que postula una hipótesis que ha hecho carne en el inconsciente colectivo: los charrúas se extinguieron (nótese que esta expresión carece de sujeto responsable al cual atribuirle la acción) porque no eran capaces de adaptarse al mundo moderno (léase: al capitalismo y al Estado-nación).

Incluso los mejor intencionados, aquellos que saben a ciencia cierta que se llevó a cabo una campaña de exterminio contra los indígenas en los años 1831-1832, han (hemos) comprado, en algún momento, la idea de que el genocidio fue completamente exitoso y que, por lo tanto, no hay más indígenas en Uruguay. Por todo esto, no es de extrañar que hasta la gente más ilustrada del país se sonría socarronamente ante la mera mención del tema indígena en Uruguay, dando por sentado que todas las etnias que lo poblaban en el pasado están extinguidas. Por ello, también, se explica la ausencia de legislación indígena en Uruguay (que junto a Surinam y las Guayanas, es el único país sudamericano que no ha ratificado el convenio 169 de la OIT) y el casi total olvido en el que han caído los guaraníes, pueblo indígena que jugó un papel fundamental tanto en la expulsión de los portugueses de la Nova Colonia do Sacramento como en la fundación de Montevideo, habitualmente atribuida a cincuenta familias canarias. 
En el resto del mundo, en cambio, desde principios de los 9o se vive un clima muy diferente en relación con los temas indígenas. Con motivo de los planes de varios Estados para la celebración del quinto centenario del "descubrimiento" de América, una serie de movilizaciones y protestas indígenas en distintas partes del mundo fueron tomando forma y, con el tiempo, los Estados y los organismos internacionales no han tenido otro remedio que responder favorablemente a sus demandas. Ese proceso tiene un punto alto en la histórica aprobación de la Declaración sobre los Derechos de los Pueblos Indígenas por parte de las Naciones Unidas en septiembre del 2007. Se trata de un tipo de legislación que pertenece al ámbito de los derechos humanos y por lo tanto tiene un rango jurídico especial. Esta clase de cambios de clima en el ámbito de los organismos internacionales y en el mundo en general tiende a ser irreversible: los logros jurídicos y sociales de los grupos otrora oprimidos quedan firmemente establecidos, primero por la ley, y luego por la práctica e implementación de esas normas.

Hoy en Uruguay se está viviendo un clima favorable en lo referente a la elaboración y aprobación de leyes que contemplan los derechos de grupos de la sociedad que han sido discriminados u oprimidos. Es de esperar que los progresos legislativos en materia de salud reproductiva y matrimonio igualitario sean tan irreversibles como los logros que se registran en el contexto internacional. En este clima, no debería ser tan difícil entender que los derechos de los indígenas son tan importantes como los de las mujeres y los gays. Con esto quiero decir que es de esperar que el gobierno apoye iniciativas como la ratificación, por parte del Estado uruguayo, del convenio 169 de la OIT, que otorga, entre otras cosas, el derecho de los indígenas a autoadscribirse como tales.

No muy lejos de Uruguay, apenas cruzando el Río de la Plata, en Argentina, los temas indígenas también han sido difíciles de elucidar y atender. A pesar de ello, en ese país se vienen produciendo cambios jurídicos importantes sobre el tema desde 1994, año en el cual, de una modificación de la Constitución por parte de la Convención Nacional Constituyente, surge un artículo (75, inciso 17) que reconoce la preexistencia de los pueblos originarios en relación con el Estado nacional. En años posteriores se aprueba, también, la ley de restitución de restos humanos (25517, en el 2001), que habilita a los pueblos indígenas a reclamar los restos de sus ancestros que se encuentran en museos y otras instituciones estatales o privadas, y el decreto presidencial 701 (del 2010), que establece que el Instituto Nacional de Asuntos Indígenas (INAI) sea el encargado de coordinar, articular y asistir el seguimiento y estudio del cumplimiento de las directivas dispuestas en dicha ley. Ese instituto, creado en 1985 como organismo descentralizado que prevé la participación de sujetos pertenecientes a diferentes pueblos originarios 
de todo el país, tiene como principal propósito el de asegurar el ejercicio de la plena ciudadanía a los integrantes de los pueblos indígenas, garantizando el cumplimiento de los derechos consagrados constitucionalmente.

Este tipo de avances es todavía más notable debido a que, como en Uruguay, en buena parte del territorio argentino (por ejemplo, en la Patagonia y en una porción significativa de La Pampa) la colonización estuvo basada en estrategias que son típicas de lo que algunos investigadores han llamado settler colonialism o colonialismo de colonos o pioneros (Veracini, "Introducing"). Se trata de un tipo de colonialismo que no se basa en la obtención de una plusvalía importante a partir de la explotación del trabajo esclavo o semiesclavo de vastas masas de indígenas (tipo de explotación que predominó en áreas de temprana colonización, en los Andes y Mesoamérica), sino en el desplazamiento o en el exterminio (si el desplazamiento falla) de los habitantes nativos del territorio. Una vez que esos aborígenes han sido desplazados o exterminados, entonces los pioneros o colonos se abocan ellos mismos a la tarea de explotar el territorio conquistado.

En estos lugares donde la base de sustentación del sistema colonial fue el desplazamiento o la eliminación de los indígenas, donde se practicaron políticas sistemáticas de exterminio (que algunos llaman "genocidio", calificación que otros, como el juez Eugenio Zaffaroni, encuentran poco afortunada), es muy difícil hablar del tema indígena de manera racional, pues es un asunto que pone en tela de juicio los cimientos mismos de la legitimidad de la soberanía del Estado-nación ${ }^{1}$. La usurpación del territorio, las políticas de exterminio (como la campaña que incluyó Salsipuedes en Uruguay y la conquista del desierto en Argentina) no son un origen que a la gente, en general, le guste recordar. Por el contrario, se intenta poner esos orígenes espurios bajo la alfombra o se los reemplaza con narrativas o mitos que en vez de un conflicto de intereses presentan alguna forma de concordia. En Estados Unidos, otro país de colonización de settlers, existe una serie de narrativas fundacionales que proponen una imagen mucho más amable del encuentro entre europeos e indígenas. Recuérdese, por ejemplo, la supuesta pero improbable historia de amor entre Pocahontas y John Smith, o la fiesta familiar norteamericana por antonomasia, Thanksgiving o Día

1 La razón por la cual el expresidente de la Corte Suprema de Argentina, Eugenio Zaffaroni, prefiere "masacre" u otros términos antes que "genocidio" es que esta última expresión, de carácter jurídico y que implica una criminalización de las conductas, tiene la desventaja de estar definida, en ese mismo ámbito jurídico, de manera poco adecuada - Zaffaroni dice, literalmente, que la definición jurídica de genocidio es un mamarracho-. Prefiere, en un espíritu más cercano al de las ciencias sociales que al de las ciencias jurídicas, hablar de masacres estatales. Véase la entrevista que le hace Mariano Nagy en el filme Tierra adentro. 
de Acción de Gracias, que presenta a las fuerzas en pugna deglutiendo de consuno un pavo y otros tipos de delicias comestibles.

En Uruguay, país donde también el territorio fue apropiado a través de una campaña de exterminio de los pobladores originarios, el tema no es menos difícil de tratar. De hecho, la aparición, hace ya unos años, de grupos de gente que se autodefinían como descendientes de charrúas (muchos de los cuales ahora se autoidentifican como charrúas a secas) provocó reacciones negativas en el público en general y en los antropólogos en particular. Algunos de los ataques más virulentos y deslegitimadores a esos grupos vinieron de los dos nombres que por lo común se identifican con la disciplina antropológica: Renzo Pi Hugarte (recientemente fallecido) y Daniel Vidart (hoy nonagenario). Estos dos conocidos autores, que gozan de considerable prestigio entre el público general (y en las altas esferas: el presidente José Mujica se enorgullece de ser amigo del segundo), pertenecen a un modo de producción intelectual anterior al que predomina en estos días en la antropología. Su forma de ver las reemergencias indígenas es bastante diferente a la prevalente en la disciplina, como puede verse incluso en los títulos de algunos de sus trabajos (Vidart).

Cada vez que Pi Hugarte se refería a las asociaciones de charrúas lo hacía diciendo que eran parte de una "charruamanía", expresión bastante peyorativa de por sí cuyo contenido negativo era acentuado por otros juicios emitidos por el antropólogo, como la acusación de racistas que les hizo a los miembros de tales asociaciones (Pi Hugarte; “Tabaré that's Right!"). Vidart, por su parte, se dedica desde hace años a sostener (correctamente) la importancia de la presencia guaraní en tierras uruguayas, antes y después de que las mismas se convirtieran en base territorial del Estado-nación actual. El problema es que lo ha hecho en desmedro de la importancia de los charrúas y se ha mofado de las asociaciones repetidamente y en cuanta ocasión ha tenido.

El clima hostil en el que surgen y se desarrollan las citadas asociaciones de indígenas es bastante generalizado si tenemos en cuenta que en el ámbito de lo político y en el de la creación popular también se producen manifestaciones anticharrúas. Me refiero, por ejemplo, a un cuplé del carnaval del 2010 de la murga Agarrate Catalina, donde se ridiculizaba a la sociedad charrúa presentándola, en boca de personajes ataviados como conquistadores españoles, como primitiva, salvaje y poco productiva — no tenían calendario, ni hacían edificios, tenían "poca civilización", "no tenían sacerdotes, no tenían religión. Pero no tenían nada: la puta que los parió" - (Agarrate Catalina). Este tipo de bromas, basadas, dicho sea de paso, en un criterio evolucionista deplorable, que ve a las sociedades como parte de una narrativa teleológica y lineal que postula una jerarquía que va de una 
menor a una mayor complejidad (como si esa gradación implicara algún tipo de valor per se), generó, como es habitual en ese marco festivo, las esperadas risas. El cuplé no se contenta con pegarles a los charrúas sino que se aboca a repetir, alegre e irresponsablemente, un mito que algunos se han dedicado a poner en duda: que los guaraníes se habrían comido a Juan Díaz de Solís y a algunos de sus hombres. El repetir lo que en otro lugar he llamado la historia oficial del descubrimiento del Río de la Plata (Verdesio, Forgotten) es un flaco favor que se le hace al pasado de la etnia guaraní y al presente de aquellos ciudadanos uruguayos que hoy reclaman una identidad indígena.

Si bien en aquel momento algunas voces defendieron con inteligencia el derecho de las agrupaciones carnavalescas a ejercer su sentido del humor con los temas que mejor les parecieran (se destaca en especial una nota de Marcelo Pereira en la diaria), todos parecen dar poca importancia al hecho de que se digan mentiras denigrantes y se usen estereotipos evolucionistas y racistas para referirse a grupos que sufrieron, históricamente, una persecución brutal y de intención exterminadora ${ }^{2}$. Traten los lectores de imaginar qué ocurriría si se dijeran esas cosas, aunque fuera en broma, sobre la comunidad judía uruguaya o sobre los afrodescendientes, o incluso sobre la comunidad gay, y piensen si no se está haciendo una excepción sospechosa (¿de racismo?) con esas manifestaciones aparentemente inocentes de los probablemente bienintencionados murguistas.

El otro ámbito hostil al que me refería más arriba es el político, donde uno de los referentes más importantes del partido Colorado, el expresidente Julio María Sanguinetti, se despachó a gusto, en más de una ocasión, en contra de la sociedad charrúa, a la que calificó de primitiva y otras lindezas. Como cualquier glosa es menos expresiva que sus dichos, acá está el párrafo inicial de la primera de sus invectivas: "No hemos heredado de ese pueblo primitivo ni una palabra de su precario idioma, ni el nombre de un poblado o una región, ni aun un recuerdo benévolo de nuestros mayores, españoles, criollos, jesuitas o militares, que invariablemente les describieron como sus enemigos, en un choque que duró más de dos siglos y les enfrentó a la sociedad hispano-criolla que sacrificadamente

2 Pereira señala, correctamente, que las palabras denigrantes en contra de los charrúas son puestas en boca de los conquistadores. Lo que no vio o no quiso decir es que en varios pasajes de los parlamentos y cantos de esos murguistas disfrazados de conquistadores se cuelan palabras, conceptos y hasta un punto de vista temporal que indican que los que están hablando son uruguayos y que lo hacen desde el presente. Y si bien afirma, correctamente, luego de un inteligente análisis del cuplé entendido como parte de una obra más vasta (no era el único cuplé que presentaban durante ese carnaval del 2010), que no se trata de un alegato en contra de los charrúas, lo cierto es que a los charrúas se les propina todo tipo de insulto y se los somete a todo tipo de befa desde una perspectiva que es claramente uruguaya y contemporánea. 
intentaba asentar familias y modos de producción, para incorporarse a la civilización occidental a la que pertenecemos" (Sanguinetti). El uso de adjetivos como "primitivo" y "precario" y la alusión a los recuerdos no-benévolos de "nuestros mayores" (es decir, de los criollos o descendientes de europeos que eran capaces de escritura y que integraban la clase dirigente de la sociedad de aquellos tiempos) revelan una toma de partido que lo lleva a presentar, tal cual lo hizo Zorrilla de San Martín, la desaparición de los indígenas como un hecho inevitable en una narrativa que propone el progreso, entendido en términos capitalistas y occidentales, como el objetivo último de toda sociedad.

Es en ese contexto hostil que surgen y se desarrollan los grupos que se autoidentifican como indígenas en el Uruguay actual. Al principio fueron las asociaciones ADENCH e India (la primera, de descendientes de charrúas; la segunda, con un espectro étnico más amplio), que estuvieron involucradas, de diferente manera y con distintos grados de protagonismo, en la restitución de los restos de Vaimaca Pirú, y más recientemente CONACHA, que coordina a varias (en este momento son nueve o diez) asociaciones de indígenas (Verdesio, "El drama"). Los lectores pueden imaginarse lo difícil que debe ser reemerger en condiciones tan adversas. Los obstáculos son varios, pero se destaca especialmente el desprestigio de todo lo indígena en Uruguay: salvajes, ignorantes, sucios, carentes de civilización, haraganes o atorrantes, y un largo etcétera. Este tipo de estigma es generalmente un efectivo freno a los intentos de autoidentificarse como indígena, como me explicaba Dora Manchado (una de las últimas hablantes de la lengua tehuelche, que al igual que sus hablantes ya era dada por extinguida) hace cuatro años en Puerto Santa Cruz (provincia de Santa Cruz, Argentina): "Hasta hace poco, si uno decía que era indio lo trataban peor que a un perro o peor que a un chilote" (Manchado) .

También está la incredulidad y el escepticismo de la gente que ha comprado las narrativas de la nación sobre el éxito absoluto de la campaña de exterminio emprendida por el Estado a comienzos de la década de 1830. Una de las preguntas que se hacen los que dan por supuesto que los indígenas han desaparecido es "¿dónde anduvieron estos 'indígenas' todo este tiempo?". A ellos se les debe contestar: estuvieron siempre aquí, pero estaban ocultos por los dispositivos de invisibilización del Estado y la sociedad dominante, por el miedo al estigma de ser

3 Chilote es la forma en que se les llama a los inmigrantes chilenos en algunas partes de la Patagonia argentina. 
indio y por el temor al escarnio público — en suma, y para citar a Dora, por miedo a ser tratados peor que perros $-{ }^{4}$.

Dicho sea todo esto para recordarles a los lectores que crean que los individuos que buscan reemerger como etnia charrúa persiguen con ello, ilegítimamente, un beneficio económico de alguna índole, que han estado, están y seguirán estando (al menos por un tiempo) sujetos a la sospecha y al escarnio públicos de una sociedad que quiere creer que "el problema del indio" en Uruguay fue resuelto hace unos ciento ochenta años. Las reemergencias indígenas, al menos en países de settler colonialism como Uruguay y Argentina, no son procesos fáciles ni placenteros para aquellos que se embarcan en ellas. Como bien ha sostenido la antropóloga argentina Claudia Briones, las identificaciones como indígenas o descendientes no son actos autónomos sino que tienen costos sociológicos y emocionales (Prólogo 15). De ello pueden dar testimonio los miembros de los movimientos de reemergencia huarpe, rankülche, tehuelche, y otros grupos indígenas que ya se daban por extintos en el vecino país. Los trabajos de investigadores como Diego Escolar, Axel Lazzari, Mariela Eva Rodríguez y tantos otros registran el largo y tortuoso camino de obstáculos que la sociedad dominante, con sus valores criollos y occidentales, les interpuso antes de que lograran el reconocimiento. Estos investigadores, al igual que su colega uruguayo Darío Arce Asenjo, no creen que el antropólogo tenga un "indiómetro" que le permita definir quién es indígena y quién no ${ }^{5}$.

Uno de los grandes problemas a los que se enfrentan los miembros de grupos reemergentes en el presente es el de su aspecto: visten en general como occidentales y su fenotipo no siempre es estereotipadamente indígena. Las razones para lo segundo están claras en sociedades donde los indígenas fueron diezmados por la fuerza y donde la inmigración fue importante y sostenida. Lo primero es también fácilmente explicable: esos sujetos reemergentes no solo viven en la sociedad occidental sino que además lo hacen en el presente. Parecería que existiera la expectativa de que los indígenas de hoy lucieran como nos imaginamos que lucían los indígenas antes del contacto. Esto es algo bastante injusto, dado que a todas las otras sociedades del planeta se les permite evolucionar sin

4 Hace ya unos años, en una celebración de alguna fecha patria, un indígena uruguayo que residía en Tacuarembó, quien vestía con algunos elementos que denotaban o pretendían denotar indigenidad, al ser preguntado sobre cómo se sentía ser indígena en una fecha de esas, respondió algo así como "y, eso de ser indio no da".

5 La agrupación Mapurbe (mapuche) de la Provincia de Río Negro, Argentina, en algún momento tuvo un "mapuchómetro" que usaba en algunas de sus actividades, para jugar y bromear con esa idea de quién y cómo define, y con base en qué criterios, quién es o puede ser indígena. 
que se les cuestione su legitimidad cultural — nadie le pide a los romanos de hoy que se vistan como un gladiador o un legionario de la época imperial, y a nadie se le ocurre que los franceses deban vestirse como lo hacían en tiempos de la Revolución francesa-.

Esta injusta y excesiva expectativa, que espera que los indígenas permanezcan idénticos a sí mismos por toda la eternidad, es muy común en aquellos países que ya mencionamos, que como Uruguay, Argentina, Estados Unidos, Canadá, Australia y Nueva Zelandia tomaron posesión de los territorios aborígenes mediante políticas de desplazamiento y exterminio. En el caso de Estados Unidos, Phil Deloria estudia, en un libro que se llama Indians in Unexpected Places (Indios en lugares inesperados), el shock que causa en la sociedad dominante el ver al legendario líder apache Gerónimo manejando un Cadillac y vistiendo un elegante traje. En el caso de Argentina, es muy común ver, ante casi todos los casos de reemergencia, una actitud similar del público en general, que reacciona desfavorablemente cuando ve a sujetos que reclaman estatus indígena usando un celular o calzando Nike. Parecería que los bienes y artefactos de la modernidad les tuvieran que estar vedados a los indígenas. Esto se debe, casi seguramente, a aquello que Johannes Fabian llamó, hace ya tres décadas, la negación de la contemporaneidad (denial of coevalness), que es una operación mental consistente en relegar al indígena del presente, ese que vemos con nuestros propios ojos, al pasado, a un momento histórico anterior de la evolución de la especie, es decir, a un momento evolutivo inferior al nuestro en una escala evolucionista. Los indígenas, aunque comparten el espacio físico con nosotros, parecen tener vedada la entrada al presente. Son, en el imaginario popular, parte de un pasado remoto.

Tal vez por eso es frecuente en la Argentina oír la expresión "indios truchos" en relación con sujetos o grupos reemergentes. La negativa a aceptar cómo son los indígenas de carne y hueso en el presente se basa, según la antropóloga brasilera Alcida Ramos, en un constructo dominante que ella llama "indio hiperreal", cuyas características nada tienen que ver con aquellos indígenas que nos encontramos en nuestra experiencia cotidiana. Esto ocurre porque la definición de quién es indígena y quién no lo es se hace desde la perspectiva del saber (por parte de historiadores, arqueólogos y antropólogos que creen poseer un indiómetro) y los valores occidentales, incluso en las legislaciones y disposiciones legales más proindígenas (como es el caso de la ya citada declaración de 2007 de la ONU). Como bien decía Edward Said con respecto a esa formación discursiva que él denominó orientalismo, eso es posible gracias a que existe una diferencia de poder entre los que elaboran el discurso y los que lo padecen. En el caso de las reemergencias indígenas, es la sociedad dominante la que decide 
cuáles son las prácticas y los rasgos que deben ser considerados como diacríticos culturales (esto es, símbolos u objetos considerados relevantes para la expresión de una identidad) que permitan la identificación de un grupo o un sujeto como indígena. Esto se debe a que los procesos de etnogénesis suponen luchas por definiciones y clasificaciones, en las cuales los grupos antagonistas poseen poder desigual (diferente capital cultural y político) para imponer las denominaciones y los significados de su preferencia (Escolar 26, 28).

Es precisamente en contra de esa tendencia de Occidente a definir o decretar las identidades de los pueblos y grupos humanos dominados o colonizados por sus Estados que se elaboraron disposiciones como el convenio 169 de la OIT y la ya citada declaración de la ONU. Se trata de derechos humanos relacionados con la defensa de las identidades y culturas de los sujetos subalternizados, razón por la cual los citados cuerpos legales les otorgan a los indígenas el derecho a autoadscribirse. Por ejemplo, el artículo 33, numeral 1, de la declaración de la ONU dice: "Los pueblos indígenas tienen derecho a determinar su propia identidad o pertenencia conforme a sus costumbres y tradiciones. Ello no menoscaba el derecho de las personas indígenas a obtener la ciudadanía de los Estados en que viven". Y el convenio 169 de la OIT, de 1989, sostiene en su artículo 2 que "la conciencia de su identidad indígena o tribal deberá considerarse un criterio fundamental para determinar los grupos a los que se aplican las disposiciones del presente Convenio"

Este tipo de normas promovidas por las organizaciones internacionales es probablemente una consecuencia de los cambios que se han ido produciendo en la forma en que los antropólogos y otros académicos conciben la cultura o la etnicidad. Pero también se debe a transformaciones que han ocurrido dentro de la academia, que a su vez son efecto de las prácticas y la militancia de varios sectores de las sociedades contemporáneas que se han abocado a realizar modificaciones tales que han redundado en una democratización significativa de la producción de sentido en relación con varias nociones, pero fundamentalmente en relación con el concepto de cultura. Como bien sostiene Briones, esto ha repercutido en una serie de cambios, en un reciclaje de la noción de cultura que se debe sobre todo a las acciones emprendidas por agentes sociales no académicos (Meta 14).

Esto ha sido acompañado por un viraje dentro de la antropología, que la ha llevado a abandonar esas concepciones de antaño, que definían la cultura como un conjunto de rasgos culturales (lengua, vestimenta, costumbres, religión, etc.)

6 En inglés el texto es mucho más claro y habla de autoidentificación: "Self-identification as indigenous or tribal shall be regarded as a fundamental criterion for determining the groups to which the provisions of this Convention apply". 
que debían estar presentes en la totalidad, o por lo menos en la franca mayoría, de las sociedades escrutadas, para que pudieran ser consideradas como indígenas. Hace ya unos cuantos años que los antropólogos entienden la cultura menos como una check list de tales rasgos que como un proceso de producción de sentido y como praxis atravesada por relaciones de poder; en suma, como lo que la gente hace (Briones, Meta 15). Pero Briones nos advierte que la cosa no termina allí: la cultura no es solo lo que la gente hace, sino que es también "un proceso social de significación que, en su mismo hacerse, va generando su propio 'régimen de verdad', acerca de lo que es cultural y [lo que] no lo es" (16). Es la propia producción cultural, entonces, y no los antropólogos ni los gobernantes, la que determina qué significados y prácticas tienen valor distintivo (16). En resumen, lo que diferencia a los grupos en contacto no depende de una suma objetiva de rasgos distintivos observables, digamos, desde un punto de vista imparcial por un observador neutral (por ejemplo, un antropólogo o un legislador), sino de aquellos que los propios actores consideran significativos, es decir, de los que ellos, y no el Estado ni los antropólogos, convierten o transforman en diacríticos o rasgos distintivos. La cultura para los antropólogos contemporáneos es, entonces, no tanto un conjunto discreto de rasgos materiales sino una praxis que se materializa en saberes, valores, modos de actuar y representaciones simbólicas (Escolar 25).

En este marco internacional en el que ganan impulso los movimientos indígenas y las reemergencias de grupos considerados hasta hace poco como extinguidos, que algunos califican como de descolonización (y otros preferimos dejar aún innominado), en Uruguay también se vive un clima acaso un poco menos hostil hacia los pueblos originarios. Es en este contexto que el colectivo agrupado en CONACHA ha logrado un importante primer paso para adquirir algo de la visibilidad perdida por los indígenas en Uruguay: conseguir que se incluyeran un par de preguntas sobre la "ancestralidad" (algunos prefieren la también inexistente, para el diccionario de la Real Academia Española, "ancestría") indígena en el censo del 2011. Esta es la primera vez que el Estado uruguayo, a través del Instituto Nacional de Estadística, se interroga por estos temas. Esto es muy importante porque, como bien señala Diego Escolar, durante la historia de algunas naciones latinoamericanas, la minimización del número de indígenas fue una estrategia de las élites locales para legitimar sus apetencias territoriales (23), lo cual condujo a lo que él llama "genocidios estadísticos," que son una de las tantas consecuencias de las permanentes luchas que se dan por la clasificación de poblaciones en esas sociedades $(24)^{7}$.

7 Escolar también sostiene que los cambios en los números de indígenas en muchos momentos de la época colonial se deben menos a su extinción que a los cambios sociales estructurales en 
Los resultados del censo uruguayo del 2011 han sido sorprendentes: cerca del $5 \%$ de la población (para ser más precisos, el 4,9\%) reconoce tener algún ancestro indígena. Ese porcentaje equivale a casi 160.ooo uruguayos, una suma un tanto abultada para un país de poco más de 3 millones de habitantes que se imagina a sí mismo como "país sin indios". Si tenemos en cuenta que en este momento los miembros de CONACHA están en el orden de los $45^{\circ}$ a 500, aproximadamente (según me informa Mónica Michelena), no debería sorprender a nadie, dadas las cifras del censo, que el número de militantes se incremente en un futuro no muy lejano. En ese caso, es de esperar que la visibilidad de estos colectivos vaya progresivamente en aumento.

Este grupo de gente ha sido ridiculizado por los antropólogos citados más arriba y por todos aquellos a quienes les cuesta tener una visión menos homogénea de la composición étnica del Uruguay. Y aun así, han perseverado en su búsqueda de reconocimiento: su intención es volverse visibles y reclamar el derecho a una identidad que los procesos históricos y los aparatos ideológicos del Estado habían vuelto impensable. Muchos de los miembros de CONACHA tienen estudios terciarios y visten como ciudadanos comunes del Estado uruguayo. Han tenido acceso a la educación formal y a los beneficios que brinda un país democrático. Pero muchos de ellos pertenecen, por el contrario, a sectores sociales depauperados. En este último caso, y como bien afirma la antropóloga Pilar Uriarte en su informe sobre racismo para el Ministerio de Educación y Cultura (MEC), "ciertas situaciones de discriminación pueden estar vinculadas al origen social y cultural, pero no estar siendo reconocidas como tales" (12). Tanto unos como otros reclaman ser reconocidos como parte de una o varias estirpes cuya sujeción y marginación sistemáticas tuvieron consecuencias de todo tipo para sus descendientes, desde el plano económico al psicológico, pasando por el social y cultural. Si bien la incredulidad y la sorna en relación con estas reivindicaciones todavía predominan en sectores importantes de la sociedad uruguaya, estos colectivos continúan su lucha y están hoy embarcados en una campaña para que el Estado uruguayo ratifique el ya citado convenio 169 de la OIT, que no solo les permite a los pueblos originarios autoidentificarse como tales, sino que además les asegura su participación en algunas instituciones (como la Comisión

el régimen colonial, que trajeron una mayor movilidad étnica y social (24). Y esa invisibilización de los indígenas se ha dado, también, gracias a que los cambios que los arqueólogos han constatado en las distintas capas de cultura material encontradas en sus excavaciones han sido interpretados como evidencia de la desaparición de etnicidades (25), lo cual es muy peligroso, pues confunde cultura material con etnicidad, que son dos conceptos que distan de ser intercambiables. 
Nacional de Patrimonio o la Dirección Nacional del Medio Ambiente) de los Estados-nación modernos.

El 9 de enero del 2013, la dirigente charrúa Mónica Michelena tuvo un primer encuentro, en un avión, con el presidente de la república, José Mujica. En esa ocasión, la dirigente le pidió que Uruguay ratifique el convenio 169 sobre derechos indígenas. Según el periodista Sebastián Cabrera, "el presidente la miró con su cara más pícara" y se produjo el siguiente diálogo:

- ¿A qué organización me dijiste que pertenecías?

- Al Consejo de la Nación Charrúa.

—No, no, ustedes están muy equivocados. No hay charrúas en Uruguay... ¡Ustedes son todos guaraníes! ¡Todos guaraníes!

Dejando de lado el ya conocido y difícil de calificar sentido del humor del anciano que dirige los destinos del país, esa pulla, por mejor intencionada que haya sido, puede ser preámbulo de otras más agresivas y descalificadoras que vendrán, seguramente, incluso luego de obtenida la tan ansiada ratificación del convenio en cuestión.

Pero no todos son nubarrones en el horizonte de los militantes por la causa charrúa: en un segundo encuentro que tuvo lugar el 2 de junio del 2013 en el consulado uruguayo en Bilbao, España, el presidente no solo atendió seriamente las demandas que le presentó Mónica Michelena en nombre de la organización que representa, sino que además la envió a hablar con el canciller Luis Almagro, quien estaba tomando mate en una sala contigua. Allí el canciller le prometió a la representante de CONACHA que antes de fines de julio del 2013 el asunto entraría al parlamento para ser debatido (CONACHA). Hasta el día de hoy eso no ha ocurrido. Es de esperar, sin embargo, que prevalezca el sentido común y Uruguay se sume a la lista de países que han ratificado el convenio.

A partir de ese momento será posible empezar a imaginar al Uruguay de una manera diferente a la que lo presenta como país monocultural. Como bien ha afirmado Pilar Uriarte en el informe para el MEC mencionado antes: "contar la historia del Uruguay únicamente desde la perspectiva de un flujo migratorio representa no solamente una falsedad histórica, sino también una forma de discriminar otros grupos que también conforman nuestra población y han realizado diferentes aportes a la identidad nacional y al patrimonio cultural de nuestro país" (2). Es de esperar que el Estado lleve adelante las recomendaciones que ese informe hace - la ratificación del convenio 169 y la creación de una secretaría de asuntos indígenas (15) - y que empiece la tarea colectiva de imaginarse como país en el que coexisten distintas culturas que, tarde o temprano, tendrán que aprender a respetarse. 


\section{Coda: un caso de estudio. Algunos puntos ciegos del sentido común uruguayo}

Una versión anterior de las páginas precedentes fue publicada en el número 7 de la revista uruguaya Lento. La misma mereció una respuesta de Aldo Mazzucchelli que apareció en Interruptor (suplemento semanal virtual de $\mathrm{H} \mathrm{En-}$ ciclopedia). Si bien son encomiables el interés y la seriedad con las que el autor trata ahí los contenidos y la forma de mi trabajo, me parece que hacer algunas puntualizaciones sobre sus análisis y su forma de razonar puede ayudarnos a ilustrar la serie de prejuicios y cegueras ideológicas que vengo discutiendo en este trabajo. El caso es interesante porque se trata de un académico que repite irreflexivamente una cadena de lugares comunes que normalmente se les suelen atribuir a otros sectores de la población.

La primera aclaración tiene que ver con el convenio 169 de la OIT que estipula, efectivamente, que su articulado se aplica a aquellos que descienden de pobladores originarios que habitaban en algún lugar del territorio en el tiempo del contacto con los europeos. También se aplica a aquellos que mantienen una continuidad cultural a través de los años que se manifiesta en la preservación de tradiciones y costumbres ancestrales. Si se siguieran estos criterios, según Mazzucchelli, se debería concluir que no hay grupo o individuo alguno en el Uruguay de hoy que pueda calificar como indígena. La realidad, que siempre es más rica que la letra de la ley, sin embargo, es un poco más compleja.

Para empezar, como señalo en el trabajo comentado por Mazzucchelli, Estados como Uruguay, Argentina o Estados Unidos llevaron a cabo un tipo de colonización que se basó en una estrategia de desplazamiento y exterminio, lo cual implica consecuencias muy negativas para los grupos indígenas que fueron víctimas de esos procedimientos. Algunas de ellas tienen que ver con la pérdida de prácticas, conceptualizaciones y tradiciones de todo tipo. El más básico principio de equidad requiere que el Estado que reprimió violentamente a los indígenas que ocupaban el territorio se abstenga de exigirles que hayan preservado las tradiciones que ese mismo Estado intentó borrar para siempre. De hecho, tanto en Estados Unidos como en Argentina, los Estados nacionales han terminado por reconocer legalmente la existencia, por medio del otorgamiento de personería jurídica, a una serie de grupos humanos que se daban por extinguidos, grupos que debido a los años de opresión y represión sufridos han visto seriamente disminuida la serie de diacríticos culturales que los caracterizaban al momento del contacto.

Por otro lado, buena parte de esos pueblos originarios se caracterizaba por una alta movilidad, razón por la cual no se les puede exigir que propongan un territorio ancestral claramente delimitado desde una perspectiva geográfica 
o cartográfica occidental. Para lidiar con este problema, lo que se ha hecho, por ejemplo, en Argentina, es iniciar un proceso (ordenado por la Ley Nacional 26.16o y conducido desde el INAI, que es el organismo estatal que se ocupa de los temas indígenas) de relevamiento de los territorios habitados y practicados por los indígenas reclamantes tanto en el pasado como en el presente ${ }^{8}$. Debe tenerse en cuenta, además, que la política de algunos Estados, como Uruguay y Argentina, se basó en desplazar a los pueblos originarios de sus territorios ancestrales, razón por la cual les sería a estos últimos muy difícil probar que haya existido una continuidad histórica en la ocupación de la tierra desde tiempos prehispánicos. Si este fuera un requisito exigido por la OIT, el mismo sería no solo poco realista sino también bastante injusto para sociedades que fueron desplazadas de las tierras que habitaban. Pero no se trata de un requisito, ya que el convenio dice claramente que sus disposiciones "se aplican" a los pueblos que tienen las características descritas en los numerales a) y b). Es decir, el convenio no les exige nada a los indígenas reclamantes: solo se limita a declarar a quiénes se aplica. Y a continuación aclara que "la conciencia de su identidad indígena o tribal deberá considerarse un criterio fundamental para determinar los grupos a los que se aplican las disposiciones del presente convenio". O sea: se estipula que, al menos en el marco legal provisto por esta norma, la autoadscripción es un criterio fundamental para determinar quién es indígena y quién no.

De todos modos es importante entender que la identidad que reclaman los indígenas víctimas de políticas estatales de exterminio no es producto de su sola voluntad, sino que se sustenta en procesos históricos a lo largo de los cuales sus derechos y su sentido de pertenencia, su modo de ser, fueron combatidos, literalmente, a muerte ${ }^{9}$. Los estudios de archivos en países como Argentina muestran una serie de acciones y estrategias llevadas a cabo por el Estado nacional que tuvieron como consecuencia la opresión, la discriminación y la invisibilización de los individuos de origen indígena que sobrevivieron a las campañas de exterminio. Esta supervivencia, esta resistencia a las estrategias

8 Relevamiento es el mapeo de los territorios que los indígenas reclaman como ancestrales. Para ello se usan los servicios de ingenieros agrimensores y otros profesionales que se dedican a medir, delimitar, etc., los territorios.

9 Como bien señala Escolar, la experiencia indica que es difícil hallar grupos que se formen sin ningún tipo de antecedente cultural, histórico o territorial (29), de modo que esos temores (implícitos en el texto de Mazzucchelli y, probablemente, en las mentes de muchos de los detractores de los grupos reemergentes en el Uruguay actual) de que se trate de grupos formados a partir de la mera voluntad de sus miembros son bastante infundados. 
de exterminio e invisibilización son las tradiciones que estos grupos de hoy pueden esgrimir como elementos de cohesión y continuidad cultural y social a través del tiempo. Es la historia y no las esencias, es la experiencia compartida de la opresión y no los rasgos culturales precontacto que reclama Mazzucchelli, lo que da un sentido de pertenencia a través del tiempo a los integrantes de los grupos que hoy se declaran indígenas. En los casos de aquellos grupos que ya no viven en comunidades, es la experiencia de diversas formas de discriminación y el haber sufrido una privación del derecho a su identidad lo que los hace unir esfuerzos para hacer reclamos en el presente. Es por el hecho de que algunos Estados modernos han reconocido este tipo de situación que, en la práctica, algunos de ellos han evaluado la legislación internacional a la luz de las trayectorias históricas de los grupos o individuos que provienen de sociedades indígenas del pasado y han decidido fallar, en varios casos (en otros, no), a favor del grupo reclamante: los huarpes, los tehuelches, los rankülches y los charrúas en Argentina, o los Wampanoag Mashpees en Massachusetts, Estados Unidos, por poner tan solo los ejemplos de reemergencia más conocidos.

El problema es que Mazzucchelli no puede percibir este tipo de lógica porque, según él, esa política de exterminio es un tema que todavía se debate encendidamente en la historiografía y la antropología uruguayas. Todo parece indicar que el autor que nos ocupa está bastante desinformado al respecto: de lo contrario, no se entiende cómo se puede negar una política y una estrategia de exterminio que ha sido reconocida (en ocasiones con orgullo) por sus propios perpetradores. Cartas e informes escritos por los mandos más altos del recién nacido Estado oriental (incluido el primer presidente constitucional, Fructuoso Rivera) así lo afirman sin prurito alguno. Casualmente, algunos de esos textos pueden encontrarse citados en una obra reciente del historiador Diego Bracco, a quien Mazzucchelli parece admirar. Por ejemplo, aparecen documentos donde Rivera expresa sus intenciones y anuncia que ya tiene un plan para llevar adelante el engaño del que serán víctimas los indígenas. Otros documentos, de tres décadas antes del comienzo de la campaña de exterminio, firmados por Jorge Pacheco, demuestran que esa intención genocida ya existía desde mucho tiempo atrás - por ejemplo, se hablaba sin vergüenza ni precaución alguna de la práctica que consistía en ejecutar prisioneros de sexo masculino-. En fin, buena parte del libro de Bracco es un exitoso intento por demostrar que muchas veces los indígenas no morían con las armas en la mano.

Esto de negar la lógica de exterminio puesta en práctica por el Estado uruguayo se relaciona con otra postura de Mazzucchelli que emparienta su mirada con la de gente como Julio María Sanguinetti, quien ya hace tiempo se viene 
dedicando a hacer una obstinada defensa de la bondad y el progresismo de los criollos que fundaron el Estado-nación uruguayo. Véase este significativo pasaje, donde Mazzucchelli se queja de

la permanente crítica denigrante que, en los últimos tiempos, algunos agentes de nuestra academia local y muchos de los practicantes de los estudios culturales en las academias extranjeras, particularmente la estadounidense, practican contra la comunidad criolla, tanto patricia como popular, de los siglos XVIII y XIX en América. Aquellos fueron colonos y agricultores, comerciantes y letrados, gente de trabajo y de luces que organizó y ganó, luchando codo a codo como soldados, la independencia de estos países: auténticos progresistas que hicieron una revolución real.

El discurso (ingenuamente?) iluminista de Mazzucchelli omite varias cosas, como por ejemplo el probado (existe amplia bibliografía sobre el tema) carácter excluyente y elitista de las luchas por la independencia, donde los sujetos de ascendencia diferente a la criolla tenían menos derechos que aquellos que sí la tenían. Pero sobre todo, se saltea precisamente el paso previo y necesario para que los criollos pudieran desarrollar esas actividades que él, adhiriendo a una narrativa evolucionista un tanto pasada de moda, considera como ejemplo de progresismo: el desplazamiento territorial y la masacre sistemática de los indígenas que vivían en el territorio que ellos pretendían ocupar y explotar. Es ese origen vitando, ese momento inicial vergonzoso, el que Mazzucchelli no quiere asumir ni aceptar. Lorenzo Veracini ha dicho que de los habitantes de los países forjados a partir de un colonialismo de colonos (settler colonialism) no se puede esperar reacciones racionales en relación con estos temas, porque niegan (como Mazzucchelli) la política de exterminio y hasta la existencia misma de los desplazados (algo que Mazzucchelli también hace al poner en duda la existencia de los charrúas en el pasado),justifican lo injustificable y defienden a capa y espada a un sector de la población de la cual se sienten descendientes y herederos (Settler).

Lo interesante de la mirada de Mazzucchelli es que los siguientes receptores de sus dardos sean los estudios culturales de origen estadounidense, debido a que, según él, habrían tenido la osadía de criticar al sector de la población que fundó tanto el Estado como la nación uruguayos. Pero no solamente son culpables de ese pecado de leso criollismo, sino que, además, sus aviesos (acaso imperialistas) designios incluyen la creación de pseudoproblemas como "la cuestión indígena" en Uruguay. Este tipo de mirada adolece de varios males, pero los más sorprendentes son la negación (de una situación de violencia que está en la historia y en los orígenes del Estado-nación uruguayo) y la paranoia (ante 
una supuesta conspiración proveniente de una entidad sospechosa y siniestra que él denomina estudios culturales), que le impiden percibir que si hay alguna disciplina culpable de que estos temas resurjan hoy con fuerza suficiente como para incomodarlo, esa disciplina se llama antropología, cuyos practicantes se involucran cada vez más en los procesos de reemergencia indígena, conscientes de que buena parte de la responsabilidad de la invisibilización de dichos pueblos les corresponde a sus antecesores en la práctica de la disciplina, y a otros académicos y productores de conocimiento, como los arqueólogos e historiadores que también contribuyeron a forjar las narrativas de la nación. Pero sobre todo, el error conceptual de Mazzucchelli es no darles crédito a otros agentes sociales que operan por fuera de la academia: los propios miembros de los grupos reemergentes. Sin ellos, sin su militancia y su persistencia, seguramente estos temas jamás habrían sido tratados ni por los antropólogos ni por los practicantes de los estudios culturales.

Los antropólogos a los que aludo son conscientes de que su disciplina puede y debe intentar rectificar errores del pasado. Una forma de hacerlo es contribuir a desandar el camino de negación y de invisibilización sufrido por diversos grupos indígenas. Lo que los estudios de esos antropólogos (que no se contentan con hacer etnografía sino que también se meten en los archivos, donde han encontrado abundante evidencia de la opresión sufrida por los indígenas a lo largo de la historia nacional) están mostrando es la continuidad no ya de los rasgos o diacríticos que los primeros cronistas percibieron en los grupos humanos que se encontraron, sino de las prácticas de discriminación y despojo que han sufrido a lo largo de la historia.

Lo importante, creo, es que más allá de las opiniones que Mazzucchelli, los antropólogos o el Estado puedan tener sobre la autenticidad (o falta de ella) de los activistas charrúas del presente, se empiece a debatir seriamente estos temas $\mathrm{y}$, de ese modo, se contribuya a promover una mayor conciencia sobre ellos en el público. Sería importante también que el Estado uruguayo ratifique el convenio 169 de la OIT y que se cree un instituto o secretaría (o como se decida llamarlo) nacional del indígena (como ya vimos que propuso la antropóloga Pilar Uriarte en su informe para el MEC sobre racismo en el Uruguay), a fin de que haya autoridades competentes para dirimir cuestiones como las que estamos discutiendo aquí. Si bien no es ideal que el Estado, sus expertos y sus funcionarios sean los que decidan sobre la autenticidad de las identidades y reclamos indígenas, es sin duda un primer paso hacia la revisibilización de estos grupos humanos que reclaman, ante todo, que se les reconozca su existencia. Digo esto porque en el fondo todo este asunto gira alrededor de dos puntos: la definición de "quién 
o quiénes son indígenas" y quién o quiénes tienen la potestad de elaborar esa definición. Por ahora, dicha definición sigue estando en manos de sujetos que no se reconocen como indígenas.

Como bien apunta Diego Escolar, es frecuente que las percepciones y los argumentos de los indígenas sobre su propia identidad no coincidan con los criterios de los saberes o disciplinas hegemónicas usados para asignar etnicidad o aboriginalidad. Es que, según ese mismo autor, las categorías étnicas y los procesos de reemergencia o etnogénesis suponen disputas de hegemonía que involucran a actores que no tienen el mismo poder: algunos agentes tienen más fuerza que otros para imponer las denominaciones y las definiciones de su preferencia (27-28). Por ello es deseable que en el futuro los propios indígenas - o aquellos que se autoadscriben como "descendientes" - puedan ser parte de la discusión sobre qué es lo que los constituye o define como tales. Pero por el momento, algunos nos conformaríamos con que el gobierno uruguayo se deje de remolonear e inicie, de una vez por todas, el proceso de ratificación del convenio 169 , que ya pronto va a cumplir veinticinco años de vigencia en el ámbito internacional.

\section{Obras citadas}

Agarrate Catalina. "Cuplé de los charrúas". YouTube 28 de agosto de 2010. Web. 15 de enero de 2014.

Arce Asenjo, Darío. "Comentarios sobre la ponencia de Daniel Vidart". Anuario de Antropología Social y Cultural en Uruguay 10 (2012): 260-261.

Bracco, Diego. Con las armas en la mano: charrúas, guenoasminuanes y guaraníes. Montevideo: Planeta, 2013.

Briones, Claudia. La alteridad del "cuarto mundo". Una deconstrucción antropológica de la diferencia. Buenos Aires: Ediciones del Sol, 1998.

-. (Meta) cultura del Estado-nación y estado de la (meta) cultura. Popayán: Jigra de Letras: Universidad del Cauca, 2005.

-. Prólogo a Los dones étnicos de la Nación. Identidades huarpe y modos de producción de soberanía en Argentina, de Diego Escolar. Buenos Aires: Prometeo, 2007.

Cabrera, Sebastián. "La garra minuana". Qué Pasa 6 de abril de 2013. Web. 1 de julio de 2013.

CONACHA. "Encuentro con el Presidente Mujica y entrevista con el canciller". Consejo de la Nación Charrúa 10 de junio de 2013. Web. 5 de julio de 2013.

Deloria, Philip. Indians in Unexpected Places. Lawrence: University Press of Kansas, 2004.

Escolar, Diego. Los dones étnicos de la nación. Identidades huarpe y modos de producción de soberanía en Argentina. Buenos Aires: Prometeo, 2007. 
Fabian, Johannes. Time and the Other. How Anthropology Makes Its

Object. Nueva York: Columbia University Press, 1983.

Lázzari, Axel. "Aboriginal Recognition, Freedom, and Phantoms. The Vanishing of the Ranquel and the Return of the Rankulche in La

Pampa". Fournal of Latin American Anthropology 8.3 (2003): 59-83.

Manchado, Dora. Comunicación personal. 2008.

Mazzucchelli, Aldo. "Nuestros charrúas posibles".

Interruptor 2013. Web. 15 de enero de 2014.

Michelena, Mónica. Comunicación personal. 2013.

Organización Internacional del Trabajo (OIT). Convenio 169.

1989. Archivo PDF. Web. 15 de enero de 2014.

Organización de las Naciones Unidas (ONU). Declaración de las Naciones Unidas sobre los derechos de los pueblos indígenas. 2007. Archivo PDF. Web. 15 de enero de 2014.

Pereira, Marcelo. "Somos una murga". La Diaria 24 de febrero de 2010. Web. 15 de enero de 2014.

Pi Hugarte, Renzo. "Sobre el charruismo. La antropología en el sarao de las seudo ciencias". Anuario de Antropología Social y Cultural en Uruguay (2002-2003): 103-121.

Ramos, Alcida. "The Hyperreal Indian". Critique of Anthropology 14.2 (1994): 153-171.

Rodríguez, Mariela Eva. De la "extinción" a la autoafirmación: Procesos de visibilización de la comunidad tehuelche Camusu Aike [Provincia de Santa Cruz, Argentina]. Tesis doctoral. Georgetown University, 2010.

Said, Edward. Orientalism. Nueva York: Vintage, 1978.

Sanguinetti,Julio María. "El charruismo". El País 19 de abril de 2009. Web. 15 de enero de 2014 .

"Tabaré that's Right! Renzo Pi Hugarte y los charrúas". Montevideo 26 de febrero de 2010. Web. 15 de enero de 2014.

Tierra adentro. Dir. Ulises de la Orden, 2011. Filme.

Uriarte, Pilar. Hacia un plan nacional contra el racismo y la discriminación. Informe final. Montevideo: Ministerio de Educación y Cultura, 2011. Archivo PDF.

Veracini, Lorenzo. "Introducing Settler Colonial Studies".

Settler Colonial Studies 1 (2011): 1-12.

-. Settler Colonialism. A Theoretical Overview. Londres: Palgrave, 2010.

Verdesio, Gustavo. "El drama de la restitución de restos humanos y sus actores en Uruguay y Argentina: el Estado, los/las arqueólogos/as y las comunidades de Pueblos Originarios". El regreso de los muertos y las promesas de oro: Usos y significados de la cultura indígena. Coord. Ivana Carina Jofré. Córdoba: Universidad de Catamarca, 2010. 123-139.

-. "Un fantasma recorre el Uruguay: la reemergencia charrúa en 
Un fantasma recorre el Uruguay: la reemergencia charrúa en un "país sin indios"

un "país sin indios"'. Lento 7 (octubre de 2013): 36-42.

-. Forgotten Conquests. Rereading New World History from the Margins. Filadelfia: Temple University Press, 2001.

Vidart, Daniel. "No hay indios en el Uruguay contemporáneo". Anuario de Antropología Social y Cultural en Uruguay 10 (2012): 251-257.

Zorrilla de San Martín, Juan. Tabaré. Montevideo: Ministerio de Instrucción Pública y Previsión Social, 1956. 